\title{
High-fat diet-related stimulation of sweetness desire is greater in women than in men despite high vegetable intake
}

\author{
Bei Zhou ${ }^{1} \uparrow$, Hisami Yamanaka-Okumura ${ }^{1, *}{ }^{\dagger}$, Chisaki Adachi ${ }^{1} \dagger$, Yuka Kawakami ${ }^{1}$, \\ Takafumi Katayama ${ }^{2}$ and Eiji Takeda ${ }^{1}$ \\ 'Department of Clinical Nutrition, Institute of Health Biosciences, University of Tokushima Graduate School, \\ Tokushima 770-8503, Japan: ${ }^{2}$ Department of Statistics and Computer Science, College of Nursing Art and Science, \\ University of Hyogo, Kobe, Japan
}

Submitted 5 December 2013: Final revision received 9 April 2014: Accepted 11 June 2014: First published online 31 July 2014

\begin{abstract}
Objective: To examine the effects of lunches with different dietary energy densities on food preferences between genders.

Design: Randomized crossover study. Participants were administered the following packed test meals once weekly on a specified day during six sessions: control (150 g of rice with a sautéed beef entrée containing $40 \mathrm{~g}$ of raw beef and $240 \mathrm{~g}$ of vegetables), high-meat/low-rice, low-vegetable, medium-fat/low-vegetable, high-fat and high-fat/low-vegetable meals. Subjective levels of sensory properties were assessed over time using visual analogue scales.

Setting: University of Tokushima Graduate School, Tokushima, Japan.

Subjects: Sixty-five men and sixty-five women matched by age and BMI.

Results: Men showed significantly stronger desires for salty and fatty foods after meals $(P<0 \cdot 05)$. Women showed a significantly stronger desire for sweetness from $2 \mathrm{~h}$ after the low-vegetable meal, and increasing fat content under highvegetable conditions caused a significant stimulated sweetness desire in women more than in men $(P<0.05)$. Moreover, after a high-meat/low-rice meal with $100 \mathrm{~g}$ of rice, sweetness desire was stronger in women $(P=0.024)$, whereas no significant differences in sweetness desire were shown between genders after another low-energy-density control meal with $150 \mathrm{~g}$ of rice.

Conclusions: Men had significantly stronger desires for salty and fatty foods, whereas women preferred sweet food after meals. The sweetness desire in women was stimulated by increasing fat content, even with a high vegetable intake. Low rice intake in a low-energy-density diet also caused a relative stimulation of sweetness desire in women.
\end{abstract}

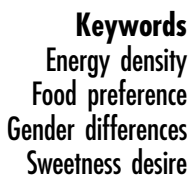

Keywords

Energy density Gender differences Sweetness desire
Nutritional strategies that can prevent weight gain are considered to be a result of controlling appetite and energy intake during normal daily life ${ }^{(1)}$. Controlled studies show that energy intake is closely associated with the energy density (ED) of the diet, which enables individuals to consume a satisfying amount of food when it is lower in $\mathrm{ED}^{(2-4)}$. Thus, reducing the ED of the total diet may be a nutritionally sound strategy for the management of body weight ${ }^{(5)}$.

Many factors affecting the sensory properties of food may contribute to the effects of ED on energy intake and eating behaviour as foods are consumed ${ }^{(6)}$. Because observational studies have indicated a relationship between food consumption and intensity of food taste ${ }^{(7)}$, attention needs to be paid to the perceptions of food-related pleasantness as well as fullness and satisfaction after food intake.

$\dagger$ These authors contributed equally to this work.
The brain controls eating behaviour and it responds differentially to food depending on factors such as body $\operatorname{mass}^{(8)}, \operatorname{mood}^{(9)}$ and age ${ }^{(10)}$. Another potential factor that cannot be neglected regarding its effects on eating behaviour is the gender difference. Men and women often have different social perceptions regarding the sensory properties of food, because women pay more attention to nutrition content than men ${ }^{(11)}$. Despite numerous studies focusing on gender-related differences in behavioural and neuronal responses to food ${ }^{(12-14)}$, little research has been published that compares specific sensory properties between genders with diet models of different ED.

Given the close association of sensory properties and dietary $\mathrm{ED}^{(15)}$, and in light of previously studied relationships of age-related variations of fullness and satisfaction with particular energy-dense diet models ${ }^{(16)}$, in the current epidemiological study our aim was to examine gender-related 


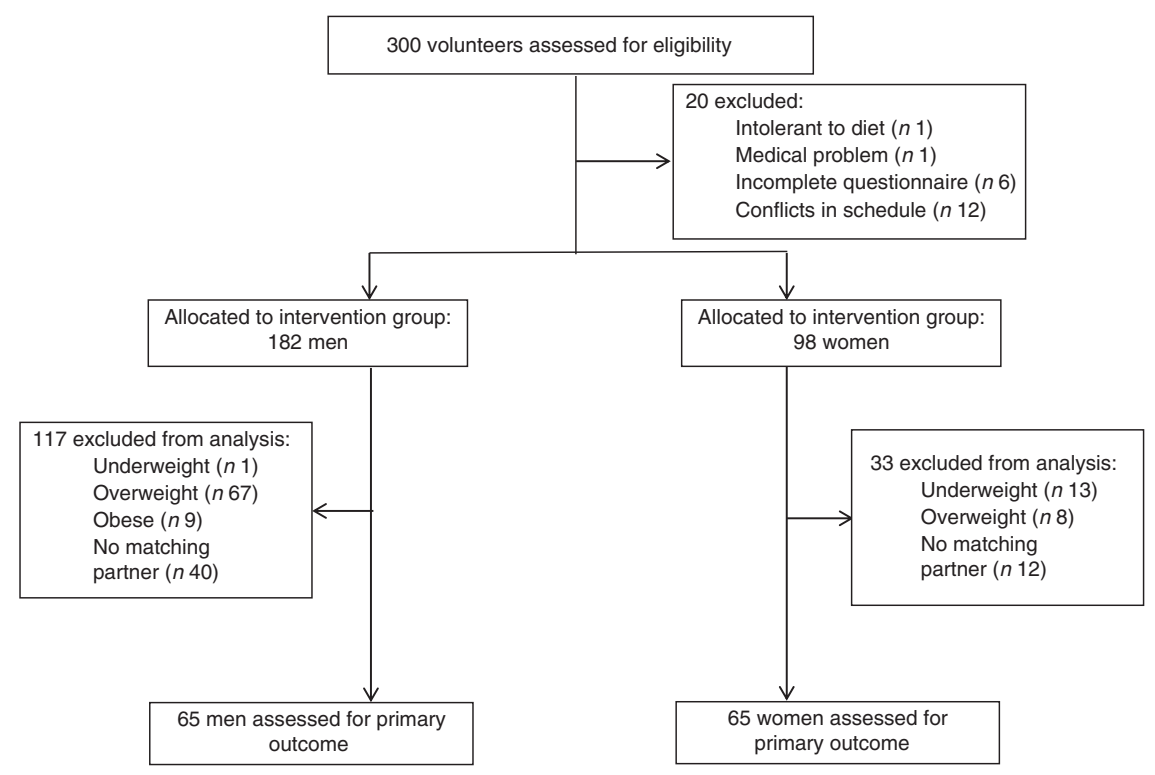

Fig. 1 Flow diagram of subject enrolment and completion of the study protocol among 300 volunteers assessed for eligibility in the present study. Halfway through the study, we excluded the following individuals: those unable to tolerate the test food items ( $n 1)$, those with poor health $(n 1)$, those sending incomplete questionnaires $(n 6)$ and those who were unexpectedly unavailable on the test dates $(n$ 12). Then the gender groups were pair matched by age and BMI to eliminate the influence of factors except gender. Finally, a total of 130 individuals (sixty-five men and sixty-five women) with normal BMl $\left(18.5 \leq \mathrm{BMI}\left(\mathrm{kg} / \mathrm{m}^{2}\right)<25.0\right)$ were included in the study

differences in the sensory properties of food after consumption of lunches with different ED.

Prior research has indicated that women give greater importance to food choice behaviours than men ${ }^{(17,18)}$. In addition, salty food intake has been shown to lead to a decrease in the pleasantness of other savoury foods in previous studies of men ${ }^{(7,19)}$, indicating that men would be satisfied with salty food. Therefore, we hypothesized that women would have greater sensitivities than men within sensory properties of food intake, and that men would prefer salty and fatty foods in their diets whereas women would have a stronger desire for sweetness. This study will further our understanding of human dietary behaviour to develop more effective gender-tailored diet models.

\section{Materials and methods}

\section{Participants}

Individuals living in Tokushima, Japan with sedentary clerical occupations and routine lifestyles who agreed to participate in the study were selected ${ }^{(16)}$. Halfway through the study, we excluded the following individuals: those unable to tolerate the test food items ( $n$ 1), those with poor health ( $n$ 1), those sending incomplete questionnaires ( $n$ 6) and those who were unexpectedly unavailable on the test dates ( $n$ 12). The gender groups were matched by age (within 10 years) and BMI (within $3 \mathrm{~kg} / \mathrm{m}^{2}$ ) to eliminate the influence of factors except gender. Finally, a total of 130 individuals (sixty-five men and sixty-five women) with normal BMI $\left(18.5 \leq\right.$ BMI $\left.\left(\mathrm{kg} / \mathrm{m}^{2}\right)<25.0\right)$ were included in the study (Fig. 1). The participants themselves reported their heights and weights according to the recorded data from their annual official medical examinations.

Each participant was provided with a detailed written explanation of the procedure of the study before we obtained informed consent. The study was conducted according to the guidelines laid down in the Declaration of Helsinki and all procedures involving human subjects were approved by the Ethics Committee of the Tokushima University Hospital. Participants were registered by the identification numbers to protect their information.

\section{Study design}

A randomized crossover design was used to investigate each test meal at lunchtime with a 1-week interval between testing sessions. Participants were asked to refrain from skipping meals, to refrain from drinking excessive alcohol and to maintain exercise at a consistent level before each scheduled session. During the study period, participants were randomly assigned into four groups for meals distribution. Group A and group B were administered meals following the sequence of lower to higher $\mathrm{ED}$, and group $\mathrm{C}$ and group $\mathrm{D}$ were administered meals in the opposite manner. A packed test lunch was systematically provided on a specified day for six consecutive weeks (Table 1$)^{(16)}$. The study was designed such that the majority of daily food and energy consumed was from the test foods, according to the 2010 Dietary Reference Intakes for Japanese ${ }^{(20)}$.

\section{Test meals}

Six types of packed lunches were used as test meals with their basic composition and appearance remaining constant. An overview of the nutritional information of the 
Table 1 Randomized crossover study design of six different types of test meals* in six experimental sessions

\begin{tabular}{lllll}
\hline Week & Group A & Group B & Group C & Group D \\
\hline 1 & Low-ED diet & Low-ED diet & High-ED diet & High-ED diet \\
& Control & Hmeat & Hfat & HfatLveg \\
2 & Medium-ED diet & Medium-ED diet & Medium-ED diet & Medium-ED diet \\
& Lveg & MfatLveg & MfatLveg \\
3 & High-ED diet & High-ED diet & Low-ED diet & Low-ED diet \\
& Hfat & HfatLveg & High-ED diet & High-ED diet \\
4 & Low-ED diet & Low-ED diet & HfatLveg & Hfat \\
& Hmeat & Control & Medium-ED diet & Medium-ED diet \\
5 & Medium-ED diet & Medium-ED diet & MfatLveg & Lveg \\
6 & MfatLveg & Lveg & Low-ED diet & Low-ED diet \\
& High-ED diet & High-ED diet & Hmeat & Control \\
\hline
\end{tabular}

Source: Zhou et al. ${ }^{(16)}$

ED, energy density.

${ }^{*}$ Control, control meal; Hmeat, high-meat/low-rice meal; MfatLveg, medium-fat/low-vegetable meal; Lveg, low-vegetable meal; Hfat, high-fat meal; HfatLveg, high-fat/low-vegetable meal.

test meals is provided in Table $2^{(16)}$. Rice was the staple food, and the main dishes were sautéed beef, steamed shiitake mushrooms with minced fish and mixed Japanese hotchpotch consisting of sweet potato, carrot, radish, dried shiitake mushrooms, bamboo shoot, lotus root and konjac. A green vegetable and kelp seaweed salad as well as tomato and broccoli jelly were also served as an integral part of each meal.

The test meals were varied by adding oil or by varying the volume of ingredients and the amounts ( $80 \mathrm{~g}$ or $240 \mathrm{~g}$ ) of raw vegetable, which were consumed after cooking. Each participant was given 1 litre of chilled water to consume ad libitum throughout the test duration until dinner. Additional water was supplied if requested, but extra food and other drinks were forbidden. The six meals were provided on each test day with varied energy and ED as follows: (i) control meal (Control), energy $2092 \mathrm{~kJ}$ $(500 \mathrm{kcal})$ and $\mathrm{ED} 3 \cdot 1 \mathrm{~kJ} / \mathrm{g}(0.8 \mathrm{kcal} / \mathrm{g})$; (ii) high-meat/ low-rice meal (Hmeat), energy $2146 \mathrm{~kJ}$ (513 kcal) and ED $3.1 \mathrm{~kJ} / \mathrm{g} \quad(0.7 \mathrm{kcal} / \mathrm{g}) ;$ (iii) low-vegetable meal (Lveg), energy $1788 \mathrm{~kJ}(427 \mathrm{kcal})$ and $\mathrm{ED} 4.1 \mathrm{~kJ} / \mathrm{g}(1.0 \mathrm{kcal} / \mathrm{g})$; (iv) medium-fat/low-vegetable meal (MfatLveg), energy $2175 \mathrm{~kJ}(520 \mathrm{kcal})$ and ED $5.0 \mathrm{~kJ} / \mathrm{g}(1.2 \mathrm{kcal} / \mathrm{g}) ;(\mathrm{v})$ high-fat meal (Hfat), energy $3750 \mathrm{~kJ}$ (896 kcal) and ED $5 \cdot 3 \mathrm{~kJ} / \mathrm{g}(1 \cdot 3$ $\mathrm{kcal} / \mathrm{g}$ ); and (vi) high-fat/low-vegetable meal (HfatLveg), energy $3446 \mathrm{~kJ}(824 \mathrm{kcal})$ and $\mathrm{ED} 7.4 \mathrm{~kJ} / \mathrm{g}(1.8 \mathrm{kcal} / \mathrm{g})^{(16)}$.

\section{Comparison assessment approaches}

The six meals, which differed in vegetable amounts and energy content, were primarily divided into two versions: (i) high-vegetable-content meals contained $240 \mathrm{~g}$ of vegetables, which included Control, Hmeat and Hfat meals; and (ii) low-vegetable-content meals contained $80 \mathrm{~g}$ of vegetables, which included Lveg, MfatLveg and HfatLveg meals. The Control, Hmeat and MfatLveg meals had low energy content with approximately $2092 \mathrm{~kJ}$ (500 kcal) but different nutritional composition in terms of the protein:fat: carbohydrate ratio, as the Control meal was converted into the Hmeat meal by decreasing the rice amount from $150 \mathrm{~g}$ to $100 \mathrm{~g}$ and increasing the raw beef amount of the sautéed beef entrée from $40 \mathrm{~g}$ to $80 \mathrm{~g}$, and the MfatLveg meal was converted from the Control meal by altering the meat with a different part of beef and decreasing the vegetable amount from $240 \mathrm{~g}$ to $80 \mathrm{~g}$. Moreover, the Control meal was converted into the Lveg meal by decreasing the vegetable amount from $240 \mathrm{~g}$ to $80 \mathrm{~g}$ and into the Hfat meal by adding oil and sauce. Likewise, the HfatLveg meal was converted from the Hfat meal by decreasing the vegetable amount by two-thirds. The vegetable amounts were weighed raw before cooking. Gender differences were compared on specific-sensory responses across the six meals.

\section{Appetite and palatability desire ratings}

Participants completed a series of $100 \mathrm{~mm}$ visual analogue scale (VAS) rating questionnaires ${ }^{(21)}$ about appetite for fullness, satisfaction and prospective demand, and palatability desire for savoury, sweet, salty and fatty foods. For example, fullness and satisfaction were rated on the 100-mm lines preceded by the questions: 'How full do you feel right now?' and 'How much satisfaction do you feel right now?', and anchored on the left by 'not at all' and on the right by 'very much', respectively. Before the study, we explained the differences between satisfaction and fullness to the participants as follows: 'The big difference is that satisfaction provides more emphasis on a mood of satiation, for example, when we enjoy the favourite food'. Prospective demand and palatability desire for savoury, sweet, salty and fatty were rated on the 100-mm lines preceded by the questions: 'How much do you think you could eat right now?', 'How much savoury food do you think you could eat right now?', 'How much sweet food do you think you could eat right now?', 'How much salty food do you think you could eat right now?' and 'How much fatty food do you think you could eat right now?', and anchored on the left by 'nothing at all' and 'a large amount' on the right, respectively. The ratings were completed after looking at the appearance of test meals before intake and at $0.5,1,2,3,4$ and $5 \mathrm{~h}$ after meals. 
Table 2 Energy and macronutrient composition of the test meals*,$\dagger$

\begin{tabular}{|c|c|c|c|c|c|c|}
\hline Item & Control & Hmeat & MfatLveg & Lveg & Hfat & HfatLveg \\
\hline \multicolumn{7}{|l|}{ Rice } \\
\hline Amount (g) & $150 \cdot 0$ & $100 \cdot 0$ & $150 \cdot 0$ & $150 \cdot 0$ & $150 \cdot 0$ & $150 \cdot 0$ \\
\hline Energy $(\mathrm{kJ} / \mathrm{kcal})$ & $1054 / 252$ & 703/168 & $1054 / 252$ & $1054 / 252$ & $1054 / 252$ & $1054 / 252$ \\
\hline ED (kJ per g/kcal per g) & $7 \cdot 0 / 1 \cdot 7$ & $7 \cdot 0 / 1 \cdot 7$ & $7 \cdot 0 / 1 \cdot 7$ & $7 \cdot 0 / 1 \cdot 7$ & $7 \cdot 0 / 1 \cdot 7$ & $7 \cdot 0 / 1 \cdot 7$ \\
\hline Protein $(\mathrm{g})$ & $3 \cdot 8$ & 2.5 & 3.8 & $3 \cdot 8$ & 3.8 & 3.8 \\
\hline Fat $(\mathrm{g})$ & 0.5 & 0.3 & 0.5 & 0.5 & 0.5 & 0.5 \\
\hline Carbohydrate (g) & $55 \cdot 7$ & $37 \cdot 1$ & $55 \cdot 7$ & $55 \cdot 7$ & $55 \cdot 7$ & $55 \cdot 7$ \\
\hline Vegetable amount (g) & 0.0 & 0.0 & 0.0 & 0.0 & 0.0 & 0.0 \\
\hline \multicolumn{7}{|l|}{ Sautéed beef } \\
\hline Amount (g) & $79 \cdot 0$ & $158 \cdot 0$ & $79 \cdot 0$ & 79.0 & 89.0 & 89.0 \\
\hline Energy (kJ/kcal) & $405 / 97$ & $810 / 194$ & $792 / 189$ & $405 / 97$ & $1177 / 281$ & $1177 / 281$ \\
\hline ED (kJ per g/kcal per g) & $5 \cdot 1 / 1 \cdot 2$ & $5 \cdot 1 / 1 \cdot 2$ & $10 \cdot 0 / 2 \cdot 4$ & $5 \cdot 1 / 1 \cdot 2$ & $13 \cdot 2 / 3 \cdot 2$ & $13 \cdot 2 / 3 \cdot 2$ \\
\hline Protein $(\mathrm{g})$ & 8.7 & $17 \cdot 4$ & 6.0 & 8.7 & 6.0 & 6.0 \\
\hline Fat $(\mathrm{g})$ & 4.5 & 9.0 & $15 \cdot 6$ & 4.5 & $25 \cdot 6$ & 25.6 \\
\hline Carbohydrate (g) & 4.7 & 9.4 & 4.5 & 4.7 & 4.5 & 4.5 \\
\hline Vegetable amount (g) & 0.0 & 0.0 & 0.0 & 0.0 & 0.0 & 0.0 \\
\hline \multicolumn{7}{|c|}{ Steamed shiitake mushrooms with minced fish } \\
\hline Amount $(\mathrm{g})$ & $49 \cdot 0$ & 49.0 & $49 \cdot 0$ & $49 \cdot 0$ & 53.0 & 53.0 \\
\hline Energy ( $\mathrm{kJ} / \mathrm{kcal})$ & $163 / 39$ & $163 / 39$ & $163 / 39$ & $163 / 39$ & $317 / 76$ & $317 / 76$ \\
\hline ED (kJ per g/kcal per g) & $3 \cdot 3 / 0 \cdot 8$ & $3 \cdot 3 / 0 \cdot 8$ & $3 \cdot 3 / 0 \cdot 8$ & $3 \cdot 3 / 0 \cdot 8$ & $6 \cdot 0 / 1 \cdot 4$ & $6.0 / 1.4$ \\
\hline Protein $(\mathrm{g})$ & $5 \cdot 0$ & 5.0 & $5 \cdot 0$ & 5.0 & 5.0 & $5 \cdot 0$ \\
\hline Fat $(\mathrm{g})$ & 0.9 & 0.9 & 0.9 & 0.9 & 4.9 & 4.9 \\
\hline Carbohydrate $(\mathrm{q})$ & 3.2 & 3.2 & 3.2 & $3 \cdot 2$ & 3.2 & 3.2 \\
\hline Vegetable amount (g) & $28 \cdot 0$ & $28 \cdot 0$ & 28.0 & 28.0 & $28 \cdot 0$ & 28.0 \\
\hline \multicolumn{7}{|c|}{ Mixed Japanese hotchpotch (sweet potato, etc.) $)$} \\
\hline Amount $(\mathrm{g})$ & $145 \cdot 0$ & $145 \cdot 0$ & $48 \cdot 3$ & $48 \cdot 3$ & $150 \cdot 0$ & 53.3 \\
\hline Energy (kJ/kcal) & $265 / 63$ & $265 / 63$ & $87 / 21$ & $87 / 21$ & $457 / 109$ & $280 / 67$ \\
\hline ED (kJ per g/kcal per g) & $1 \cdot 8 / 0 \cdot 4$ & $1 \cdot 8 / 0 \cdot 4$ & $1 \cdot 8 / 0 \cdot 4$ & $1 \cdot 8 / 0 \cdot 4$ & $3 \cdot 1 / 0 \cdot 7$ & $5 \cdot 3 / 1 \cdot 3$ \\
\hline Protein $(\mathrm{g})$ & $2 \cdot 0$ & $2 \cdot 0$ & 0.7 & 0.7 & $2 \cdot 0$ & 0.7 \\
\hline Fat $(\mathrm{g})$ & $1 \cdot 2$ & 1.2 & 0.4 & 0.4 & $6 \cdot 2$ & $5 \cdot 4$ \\
\hline Carbohydrate (g) & $13 \cdot \overline{2}$ & $13 \cdot \overline{2}$ & 4.4 & 4.4 & $13 \cdot 2$ & 4.4 \\
\hline Vegetable amount (g) & 78.0 & $78 \cdot 0$ & $26 \cdot 0$ & $26 \cdot 0$ & 78.0 & $26 \cdot 0$ \\
\hline \multicolumn{7}{|c|}{ Green vegetable and kelp seaweed salad } \\
\hline Amount (g) & $106 \cdot 0$ & $106 \cdot 0$ & $30 \cdot 0$ & $30 \cdot 0$ & $115 \cdot 0$ & 39.0 \\
\hline Energy $(\mathrm{kJ} / \mathrm{kcal})$ & $44 / 11$ & $44 / 11$ & $13 / 3$ & $13 / 3$ & $391 / 94$ & $360 / 86$ \\
\hline ED (kJ per g/kcal per g) & $0.4 / 0 \cdot 1$ & $0.4 / 0 \cdot 1$ & $0.4 / 0 \cdot 1$ & $0.4 / 0.1$ & $3.4 / 0 \cdot 8$ & $9 \cdot 2 / 2 \cdot 2$ \\
\hline Protein $(\mathrm{g})$ & 0.6 & 0.6 & 0.2 & 0.2 & 0.6 & 0.2 \\
\hline Fat $(\mathrm{g})$ & 0.1 & 0.1 & 0.0 & 0.0 & $9 \cdot 1$ & 9.0 \\
\hline Carbohydrate $(\mathrm{g})$ & $2 \cdot 5$ & 2.5 & 0.7 & 0.7 & 2.5 & 0.7 \\
\hline Vegetable amount (g) & 58.0 & 58.0 & $14 \cdot 0$ & $14 \cdot 0$ & 58.0 & $14 \cdot 0$ \\
\hline \multicolumn{7}{|l|}{ Tomato and broccoli jelly } \\
\hline Amount $(g)$ & $140 \cdot 0$ & $140 \cdot 0$ & $76 \cdot 0$ & $76 \cdot 0$ & $145 \cdot 0$ & $81 \cdot 0$ \\
\hline Energy $(\mathrm{kJ} / \mathrm{kcal})$ & $161 / 39$ & $161 / 39$ & $66 / 16$ & $66 / 16$ & $354 / 85$ & $259 / 62$ \\
\hline ED (kJ per g/kcal per g) & $1 \cdot 2 / 0 \cdot 3$ & $1 \cdot 2 / 0 \cdot 3$ & $0.9 / 0.2$ & $0.9 / 0.2$ & $2 \cdot 4 / 0 \cdot 6$ & $3 \cdot 2 / 0 \cdot 8$ \\
\hline Protein $(\mathrm{g})$ & 5.0 & $5 \cdot 0$ & 2.9 & 2.9 & $5 \cdot 0$ & 2.9 \\
\hline Fat $(\mathrm{g})$ & 0.4 & 0.4 & 0.1 & $0 \cdot 1$ & 5.4 & $5 \cdot 1$ \\
\hline Carbohydrate (g) & 5.5 & 5.5 & 1.3 & $1 \cdot 3$ & 5.5 & 1.3 \\
\hline Vegetable amount (g) & $76 \cdot 0$ & $76 \cdot 0$ & $12 \cdot 0$ & $12 \cdot 0$ & $76 \cdot 0$ & $12 \cdot 0$ \\
\hline \multicolumn{7}{|l|}{ Total } \\
\hline Weight (g) & $669 \cdot 0$ & 698.0 & $432 \cdot 3$ & $432 \cdot 3$ & $702 \cdot 0$ & 465.3 \\
\hline Energy $(\mathrm{kJ} / \mathrm{kcal})$ & $2092 / 500$ & $2146 / 513$ & $2175 / 520$ & $1788 / 427$ & $3750 / 896$ & $3446 / 824$ \\
\hline ED (kJ per g/kcal per g) & $3 \cdot 1 / 0 \cdot 8$ & $3 \cdot 1 / 0 \cdot 7$ & $5 \cdot 0 / 1 \cdot 2$ & $4 \cdot 1 / 1 \cdot 0$ & $5 \cdot 3 / 1 \cdot 3$ & $7 \cdot 4 / 1 \cdot 8$ \\
\hline \multicolumn{7}{|l|}{ Protein } \\
\hline (g) & $25 \cdot 0$ & $32 \cdot 4$ & 18.4 & $21 \cdot 1$ & $22 \cdot 3$ & 18.4 \\
\hline$\%$ & $20 \cdot 0$ & $25 \cdot 3$ & $14 \cdot 2$ & 19.8 & $10 \cdot 0$ & 9.0 \\
\hline \multicolumn{7}{|l|}{ Fat } \\
\hline (g) & 7.5 & 11.8 & 17.4 & $6 \cdot 3$ & $51 \cdot 6$ & $50 \cdot 4$ \\
\hline$\%$ & 13.5 & 20.8 & $30 \cdot 2$ & $13 \cdot 3$ & 51.8 & $55 \cdot 1$ \\
\hline \multicolumn{7}{|l|}{ Carbohydrate } \\
\hline (g) & $84 \cdot 7$ & $70 \cdot 8$ & 69.8 & 69.9 & 84.5 & $69 \cdot 8$ \\
\hline$\%$ & $66 \cdot 5$ & 53.9 & $55 \cdot 6$ & $66 \cdot 9$ & 38.2 & 35.9 \\
\hline Vegetable amount (q) & 240.0 & $240 \cdot 0$ & $80 \cdot 0$ & $80 \cdot 0$ & 240.0 & 80.0 \\
\hline Dietary fibres $(\mathrm{g})$ & $7 \cdot 6$ & 7.5 & 2.9 & 2.9 & $7 \cdot 6$ & 2.9 \\
\hline Salt $(g)$ & $2 \cdot 3$ & 2.9 & 1.8 & 1.8 & $2 \cdot 3$ & $1 \cdot 8$ \\
\hline
\end{tabular}

Source: Zhou et al. ${ }^{(16)}$

ED, energy density.

* Six versions of each meal were served. All values were calculated on the basis of test meals.

†Control, control meal; Hmeat, high-meat/low-rice meal; MfatLveg, medium-fat/low-vegetable meal; Lveg, low-vegetable meal; Hfat, high-fat meal; HfatLveg, high-fat/low-vegetable meal.

$\ddagger$ Mixed Japanese hotchpotch, a traditional Japanese dish similar to a Western-style stew or hot pot with all ingredients simmered in one pot. 


\section{Data analysis}

To evaluate the gender differences in specific-sensory responses, we calculated the area under the curve (AUC) of VAS ratings for gender-related sensory properties with different meals. Unpaired $t$ tests were used to assess gender differences on sensory properties by evaluating VAS ratings and AUC of VAS ratings for the six meals. ANOVA with repeated measures and Bonferroni post hoc tests evaluated the ratings of sensations with test meals from $0 \mathrm{~h}$ to $5 \mathrm{~h}$ after meals and the differences of sensation ratings among test meals in each group.

In our preliminary analysis, $15 \mathrm{~mm}$ VAS difference with $20 \mathrm{~mm}$ SD was expected, i.e. effect size of $0 \cdot 75$. For example, ensuring a two-tailed $\alpha$ error of 0.05 and $\beta$ error of $0 \cdot 20$, the required sample size is twenty-nine participants per comparison group.

All statistical analyses were performed using statistical software package SPSS version $16 \cdot 0$ (2007). The results are reported as means with their standard errors and were considered significant at $P<0 \cdot 05$.

\section{Results}

\section{Participants}

Participant characteristics, including mean age, weight, height and BMI, are shown in Table 3. The two gender groups included sixty-five men and sixty-five women who were matched by age and BMI to eliminate these influence factors. Thus, there were no significant differences in BMI and age between the gender groups.

\section{Comparisons of gender differences on sensory properties with test meals}

Ratings of sensory properties between genders with test meals are shown in the online supplementary material (Supplemental Table 1 and Supplemental text) and Fig. 2. Overall, women had a significantly stronger desire for sweetness than men, whereas men had stronger desires for salty and fatty foods than women, after meals.

From $3 \mathrm{~h}$ after the Lveg meal, the desire for savoury food was significantly higher in women than in men $(P<0.05)$. AUC of VAS ratings for savoury desire were significantly higher in women than in men with the Lveg meal $(P=0 \cdot 033)$. AUC for prospective demand were significantly lower in women than in men with the Control meal $(P=0.006)$, and AUC of VAS ratings for fullness were significantly higher in women than in men with the Control meal $(P=0 \cdot 015)$.

Similarly, VAS ratings of sweetness desire after meals were significantly higher in women than in men $(P<0 \cdot 05)$ except with the Control meal, which showed that VAS ratings of sweetness desire in women at $0 \cdot 5-2 \mathrm{~h}$ after meals were significantly lower than those before meals $(P<0 \cdot 01)$. In contrast, sweetness desire with the low-ED Hmeat diet was stronger in women than in men from $3 \mathrm{~h}$ after meals $(P<0.05)$. Although ratings of fullness $(P<0.001)$ and satisfaction $(P=0.014)$ were also significantly higher in women than in men after intake of the Hfat meal at $0.5 \mathrm{~h}$, sweetness desire was stronger in women than in men from $4 \mathrm{~h}$ after meals $(P<0.05)$. Ratings of sweetness desire with the Lveg, MfatLveg and HfatLveg meals were significantly higher in women than in men from $2 \mathrm{~h}(P=0.043), 4 \mathrm{~h}$ $(P=0.019)$ and $5 \mathrm{~h}(P=0.021)$ after meals, respectively. Moreover, AUC of VAS ratings for sweetness desire were significantly higher in women than in men with the Hmeat $(P=0.024)$ and Lveg $(P=0.008)$ meals.

Ratings of salty and fatty desire were significantly lower in women than in men with high-vegetable-content meals at $0 \cdot 5-3 \mathrm{~h}$ after meals, especially with the Control meal, which showed significance at $0.5-5 \mathrm{~h}$ after meals $(P<0.05)$. In addition, AUC of VAS ratings for the desire for salty food were significantly higher in men than in women $(P<0.05)$, except with the Lveg meal, and AUC of VAS ratings for the desire for fatty food were significantly higher in men than in women regardless of meals $(P<0.05)$.

\section{Sensory response differences with test meals in each gender group}

As shown in Figs 3 and 4, meals with higher vegetables provided greater fullness and satisfaction regardless of gender, although response to meals changed within a smaller range for men than for women.

\section{Sensory response in men}

Appetite ratings for fullness and satisfaction were significantly higher with the Hfat meal than with the HfatLveg meal at $0.5 \mathrm{~h}(P=0.001)$ and $1 \mathrm{~h}(P=0.019)$ after meals. Ratings for prospective demand were significantly lower

Table 3 Characteristics of participants in the randomized crossover study, Tokushima, Japan*

\begin{tabular}{|c|c|c|c|c|c|c|}
\hline \multirow[b]{2}{*}{ Characteristic } & \multicolumn{2}{|c|}{ Total $(n 130)$} & \multicolumn{2}{|c|}{ Men $(n 65)$} & \multicolumn{2}{|c|}{ Women ( $n$ 65) } \\
\hline & Mean & SE & Mean & $\mathrm{SE}$ & Mean & SE \\
\hline Age (years) & 39.9 & 0.8 & $40 \cdot 1$ & $1 \cdot 1$ & $39 \cdot 6$ & $1 \cdot 1$ \\
\hline Height $(\mathrm{cm})$ & $165 \cdot 1$ & 0.8 & 171.6 & 0.7 & 158.6 & 0.7 \\
\hline Weight (kg) & $58 \cdot 3$ & 0.7 & 63.5 & 0.8 & 53.1 & 0.6 \\
\hline BMI $\left(\mathrm{kg} / \mathrm{m}^{2}\right)$ & 21.3 & 0.1 & 21.5 & 0.2 & $21 \cdot 1$ & 0.2 \\
\hline
\end{tabular}

*There were no significant differences in BMI and age between men and women. 
AUC for fullness

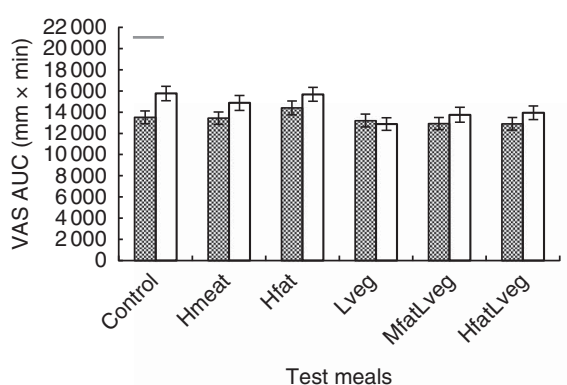

AUC for prospective demand

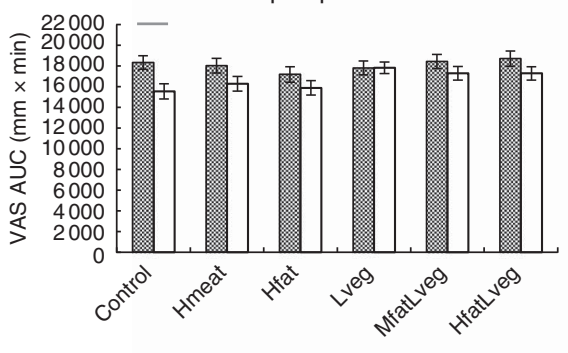

Test meals

AUC for salty desire

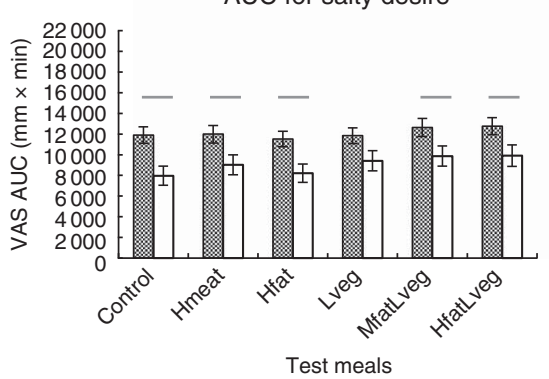

AUC for satisfaction

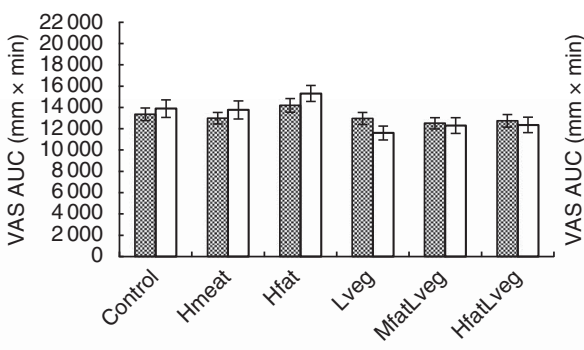

Test meals
AUC for sweetness desire

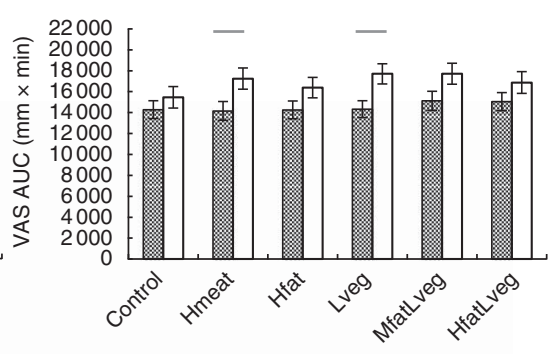

Test meals
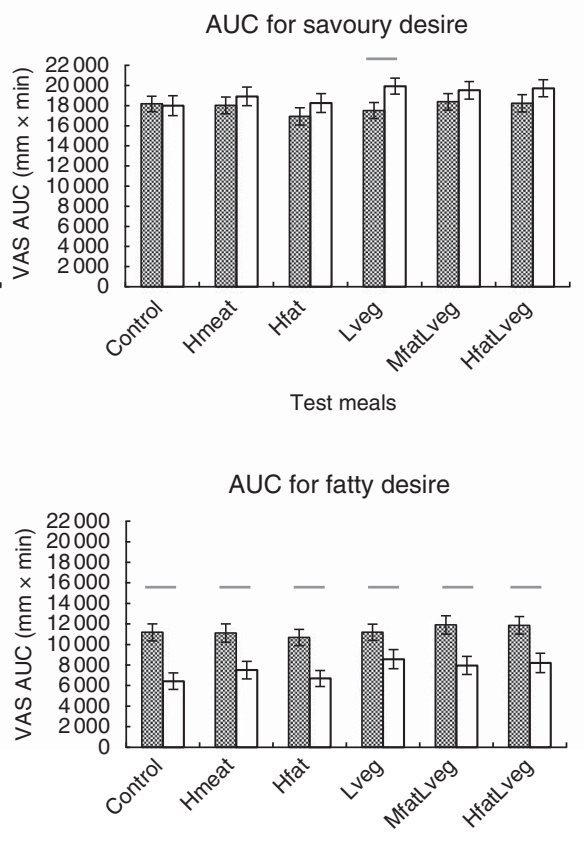

Test meals

Fig. 2 Areas under the curve (AUC) of visual analogue scale (VAS) ratings (means with their standard errors represented by vertical bars) for sensory properties after consumption of different test meals, by gender, in a randomized crossover study of sixty-five men (回) and sixty-five women ( $\square$ ), matched by age and BMI, Tokushima, Japan. AUC were calculated over the entire period from 0 to $5 \mathrm{~h}$ after meals. Differences $(P<0.05)$ between genders were assessed by using unpaired $t$ tests and are represented by the horizontal lines. Control, control meal; Hmeat, high-meat/low-rice meal; MfatLveg, medium-fat/low-vegetable meal; Lveg, low-vegetable meal; Hfat, high-fat meal; HfatLveg, high-fat/low-vegetable meal

with the Hfat meal than with the HfatLveg meal at $1 \mathrm{~h}$ $(P=0.008)$ and $2 \mathrm{~h}(P=0.023)$ after meals. There were no significant differences for palatability desire except for savoury $(P=0.044)$ and fatty foods $(P=0.026)$, which were significantly lower with the Hfat meal than with the HfatLveg meal at $1 \mathrm{~h}$ after meals.

\section{Sensory response in women}

Appetite ratings for fullness were significantly higher with the Control meal than with the MfatLveg meal or the HfatLveg meal at $0.5 \mathrm{~h}$ and $1 \mathrm{~h}$ after meals $(P<0.01)$. Ratings for satisfaction were significantly higher with the Control meal than with the MfatLveg meal $(P=0.008)$ or the HfatLveg meal $(P=0.007)$ at $0.5 \mathrm{~h}$ after meals. Ratings for savoury and fatty food desire were significantly lower with the Control meal than with the Lveg meal at $1 \mathrm{~h}$
$(P=0.044)$ and $3 \mathrm{~h}(P=0.010)$ after meals, respectively. Sweetness desire ratings were significantly lower with the Control meal than with the MfatLveg meal at $1 \mathrm{~h}$ after meals $(P=0.025)$.

\section{Discussion}

The present study is the first to examine the effects of dietary ED on a variety of sensory properties of food with typical Japanese diets between genders using a large sample size and a population-based prospective design.

The results from the study demonstrate gender differences in sensory properties of food after different meals. The study had three main findings: (i) meals with higher vegetables provided greater fullness and satisfaction 

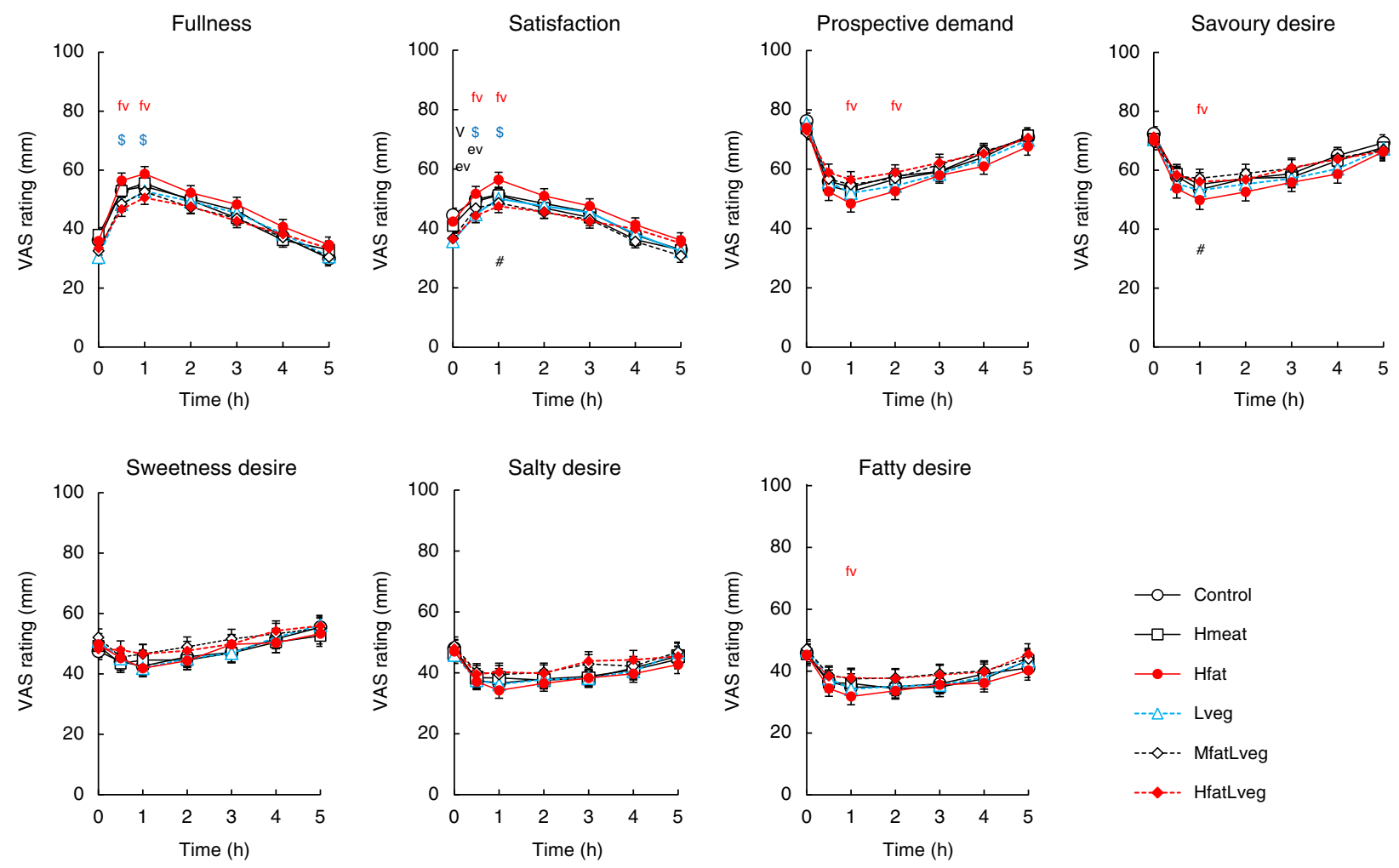

Fig. 3 Visual analogue scale (VAS) ratings (means with their standard errors represented by vertical bars) for sensory properties after consumption of different test meals in sixty-five men participating in a randomized crossover study, Tokushima, Japan. Differences $(P<0.05)$ among the meals at each time point were assessed by using repeated-measures ANOVA followed by Bonferroni post hoc tests: V, Control v. MfatLveg; ev, Control v. Lveg; fv, Hfat $v$. HfatLveg; \$, Lveg v. Hfat; \#, MfatLveg v. Hfat. Control, control meal; Hmeat, high-meat/low-rice meal; MfatLveg, medium-fat/low-vegetable meal; Lveg, low-vegetable meal; Hfat, high-fat meal; HfatLveg, high-fat/low-vegetable meal

regardless of gender; (ii) although responses to meals changed within a smaller range for men than for women, men had stronger desires for salty and fatty food than women after meals; and (iii) women had stronger desire for sweetness than did men, except after the Control meal with $150 \mathrm{~g}$ of rice, and a lower rice intake in the low-ED diet also stimulated sweetness desire in women more than in men.

Sensory properties of food, including appetite factors and palatability desire, play major roles in the selection of diets, which influences food intake. Fullness is the feeling that persists after eating to suppress further food consumption, whereas satisfaction emphasizes a mood that leads to the termination of eating. Both fullness and satisfaction influence the prospective demand, which regulates appetite ${ }^{(22)}$. Simultaneously, savoury, sweet, salty and fatty elements are the major constituents of palatability in a daily diet.

ED appears to be a major dietary factor influencing food intake $^{(23,24)}$. Evidence in our previous study also suggests that low-ED diets promote fullness and satisfaction and may help to control weight ${ }^{(16)}$. As predicted, sensoryspecific responses in the present study changed within a smaller range in men than in women probably due to women's greater concern about diet. One possibility is that women are not only more concerned about their health, but are also more likely to translate these concerns into the selection of their daily diets ${ }^{(12,17,18)}$.

Taste preference which reflects palatability of foods is also associated with daily intake ${ }^{(25-27)}$. Researchers in one study speculated that compared with men, women have better gustatory responses with the sweet taste and worse gustatory responses with the salt taste ${ }^{(28)}$, which is also supported in the current study. Salt taste, as an essential element during cooking, can balance flavour in food. Salt preference is mostly influenced by dietary restraint ${ }^{(29)}$ and exercise $^{(30)}$. Additionally, habitual intake is another factor affecting salt preference ${ }^{(31,32)}$. In the present study, men showed stronger desire for salty and fatty foods than women after intake, whereas women showed stronger desire for sweet food than men, probably due to the taste differences between genders ${ }^{(28)}$. A previous study found that gene variations in the presence of receptor proteins could play a role related to the differences in fat preferences between genders ${ }^{(26)}$. However, compared with sweet and fat appetite acquired from early childhood ${ }^{(33)}$, salt preference is more complex and less understood ${ }^{(34)}$. Moreover, sweet taste in foods, which is considered to be an important sensory property of food for nutritive energy, has an undeniable sensory appeal along with the 

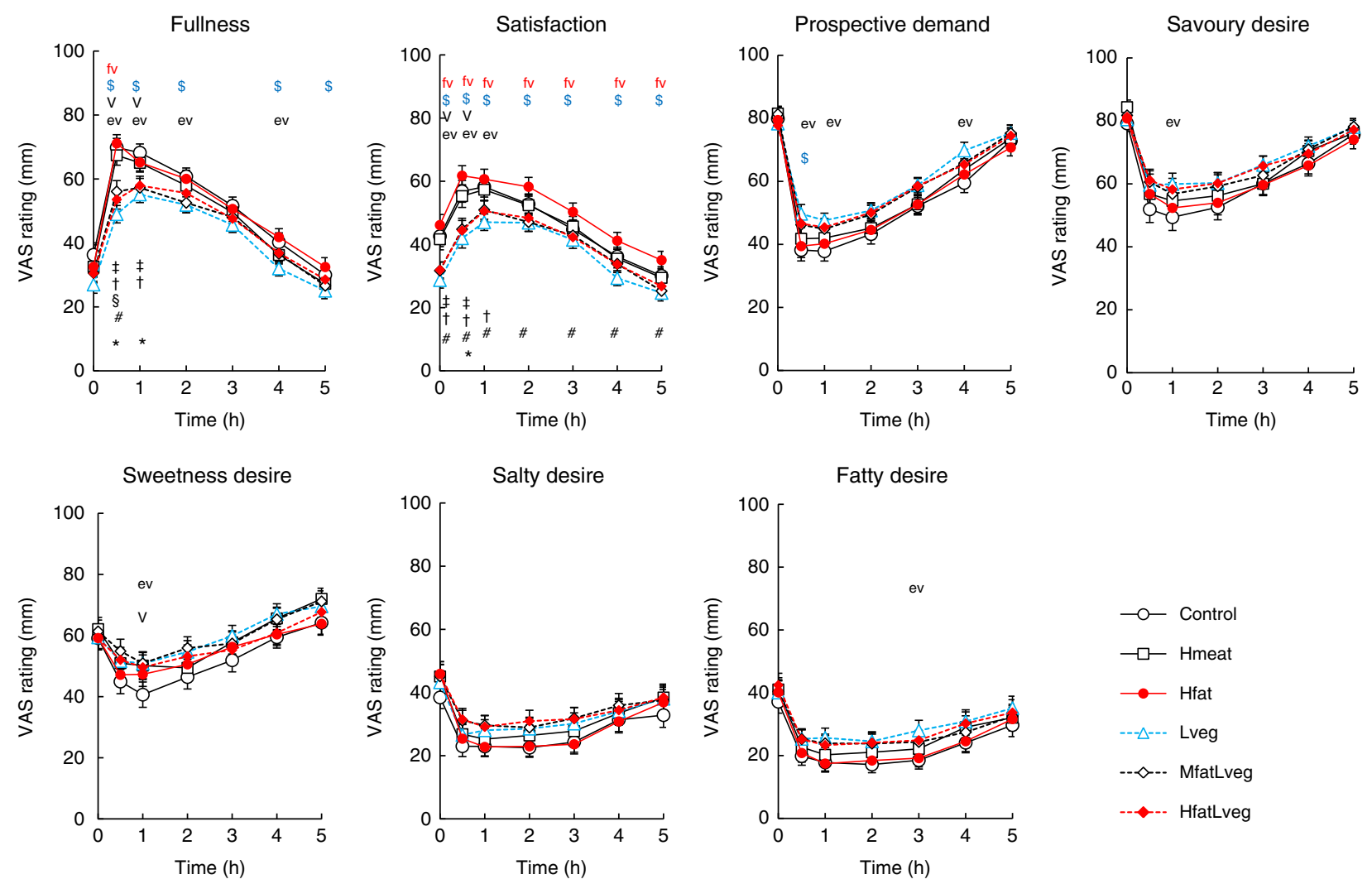

Fig. 4 Visual analogue scale (VAS) ratings (means with their standard errors represented by vertical bars) for sensory properties after consumption of different test meals in sixty-five women participating in a randomized crossover study, Tokushima, Japan. Differences $(P<0.05)$ among the meals at each time point were assessed by using repeated-measures ANOVA followed by Bonferroni post hoc tests: V, Control v. MfatLveg; ev, Control v. Lveg; ${ }^{*}$, Control v. HfatLveg; fv, Hfat $v$. HfatLveg; \$, Lveg v. Hfat; †, Hmeat $v$. MfatLveg; †, Hmeat $v$. Lveg; §, Hmeat $v$. HfatLveg; \#, MfatLveg v. Hfat. Control, control meal; Hmeat, high-meat/low-rice meal; MfatLveg, medium-fat/ low-vegetable meal; Lveg, low-vegetable meal; Hfat, high-fat meal; HfatLveg, high-fat/low-vegetable meal

fatty taste ${ }^{(35)}$. Earlier findings indicated that adding flavour and improving food texture with fat could increase the palatability of meals ${ }^{(36,37)}$. On the other hand, vegetables are important components of the diet that can help individuals reach a sufficient fullness without decreasing food volume due to the lower $\mathrm{ED}^{(5,16)}$.

In the low-vegetable-content meals, VAS data show that women had stronger desire for sweetness than men after meals, especially with the Lveg meal, which stimulated higher sweetness desire in women than in men from $2 \mathrm{~h}$ after the meal. However, with increased fat content in the MfatLveg meal, the sweetness desire was higher in women than in men starting from $4 \mathrm{~h}$ after meals. With the additional increase in fat content by the addition of oil in the Hfatlveg meal, no significant differences between genders in the sweetness desire were shown until $5 \mathrm{~h}$ after the meal, suggesting that fat plays an important role without sufficient vegetables in a practical diet. Notably, in the high-vegetablecontent meals, no significant differences were observed between genders after intake of the Control meal, even with a low energy content of $2092 \mathrm{~kJ}$ (500 kcal). Interestingly, when the meal was changed to the Hfat meal with an increased fat content by adding oil, sweetness desire was higher in women than in men from $4 \mathrm{~h}$ after the meal.
Fat, as an important factor increasing palatability in a meal, enhances sensitivity to satisfaction signals by elevating leptin and insulin signalling in the central nervous system ${ }^{(38,39)}$. The pleasurable aspects of fat consumption provide a hedonic preference for food due to the rewarding and reinforcing properties of some dietary fats ${ }^{(40,41)}$. The current study reflects that fat might suppress sweetness desire in a diet with vegetable content as low as $80 \mathrm{~g}$, whereas in a diet with sufficient vegetable content such as $240 \mathrm{~g}$, increased fat content might stimulate the redundant sweetness desire. This stimulation is probably due to initiating a vicious cycle from the increased palatability of the diet. A previous study reported that the increased fat content that promotes the sensory properties of the diet causes insulin/leptin resistance, resulting in more food consumption ${ }^{(42)}$.

In addition, in the low-ED Hmeat diet containing $240 \mathrm{~g}$ of vegetables, higher sweetness desire was stimulated in women more than in men from $3 \mathrm{~h}$ after the meal, mainly due to the lower ( $100 \mathrm{~g}$ ) rice intake. Rice is a major dietary staple, forms the basis of the dietary pattern in most Asian countries and is traditionally consumed with other dishes $^{(43)}$. The low-ED Control diet included $150 \mathrm{~g}$ of rice, providing sufficient carbohydrate, compared with the high-meat/low-rice meal. However, it resulted in no 
significant differences for sweetness desire between genders. Taken together, the results indicate that sweetness desire, especially for women, is also stimulated by decreasing rice intake in the low-ED diet model.

The strengths of the present study are that it elucidates sensory property differences between genders and also explores practical dietary advice of low-ED diet models. The test meals provide the flexibility to make a diet that is highly satiating without increased fat content or additional oil by increasing vegetables, thus controlling energy intake. Consumption of $240 \mathrm{~g}$ of vegetables and $150 \mathrm{~g}$ of rice in a $2092 \mathrm{~kJ}$ (500 kcal) lunch could be sufficiently satisfying and might potentially lower the prevalence of obesity because no additional oil was used in the low-ED model and there was no redundant sweetness desire after intake. One of the limitations of the study is the single staple food. Results with a Western diet model with bread as the staple food might be different. Another limitation is that the participants in the current analysis were all clerical staff with normal BMI and the patterning of gender differences may be different in other populations who have varied activities or BMI. More extensive research is needed to address these points.

\section{Conclusion}

The present study suggests that increasing vegetable intake in a diet is effective to enhance fullness and satisfaction regardless of gender. Men had stronger desire for salty and fatty foods, whereas women preferred sweetness after meals. Sweetness desire, especially for women, was stimulated by high fat content, even with high vegetable intake. In other words, fat appears to perform a redundant role to stimulate sweetness desire in a practical diet with high vegetable intake (e.g. 240 g). Furthermore, low rice intake in low-ED diets also stimulated sweetness desire in women more than in men. Our results provide useful insights into the role of sensory properties on food intake across genders, although more studies are needed.

\section{Acknowledgements}

Acknowledgements: The authors appreciate the cooperation of the volunteers in Tokushima who participated in the study. Financial support: This study was supported by a scientific research project grant from the Developing Innovation Systems Regional Innovation Strategy Support Program and Grant-in-Aid for Scientific Research (B) in Japan (grant number 24300256) (to E.T. and H.Y.-O.). The funder had no role in the design, analysis or writing of this article. Conflict of interest: None. Authorship: B.Z., H.Y.-O. and C.A. contributed equally to this work. B.Z. collected, analysed and interpreted the data and wrote the manuscript; H.Y.-O. contributed to the entire design of the study and interpreted the data; C.A. contributed to the data collection and management; Y.K. conducted the study and collected the data; T.K. supervised the statistical analysis and provided consultation throughout; and E.T. contributed to the provision of significant advice and the critical revision of the manuscript. All authors reviewed and approved the final manuscript. Ethics of buman subject participation: The study was conducted according to the guidelines laid down in the Declaration of Helsinki and all procedures involving human subjects were approved by the Ethics Committee of the Tokushima University Hospital. Participants were registered by the identification numbers to protect their information.

\section{Supplementary material}

To view supplementary material for this article, please visit http://dx.doi.org/10.1017/S1368980014001426

\section{References}

1. Melanson K (2004) Food intake regulation in body weight management: a primer. Nutr Today 39, 203-215.

2. Bell EA, Castellanos VH, Pelkman CL et al. (1998) Energy density of foods affects energy intake in normalweight women. Am J Clin Nutr 67, 412-420.

3. Bell EA \& Rolls BJ (2001) Energy density of foods affects energy intake across multiple levels of fat content in lean and obese women. Am J Clin Nutr 73, 1010-1018.

4. Stubbs RJ, Johnstone AM, O'Reilly LM et al. (1998) The effect of covertly manipulating the energy density of mixed diets on ad libitum food intake in 'pseudo freeliving' humans. Int J Obes Relat Metab Disord 22, 980-987.

5. Rolls BJ, Drewnowski A \& Ledikwe JH (2005) Changing the energy density of the diet as a strategy for weight management. J Am Diet Assoc 105, 5 Suppl. 1, S98-S103.

6. Bell EA, Roe LS \& Rolls BJ (2003) Sensory-specific satiety is affected more by volume than by energy content of a liquid food. Physiol Behav 78, 593-600.

7. Rolls ET, Rolls BJ \& Rowe EA (1983) Sensory-specific and motivation-specific satiety for the sight and taste of food and water in man. Physiol Behav 30, 185-192.

8. Killgore WD \& Yurgelun-Todd DA (2005) Body mass predicts orbitofrontal activity during visual presentations of high-calorie foods. Neuroreport 16, 859-863.

9. Killgore WD \& Yurgelun-Todd DA (2006) Affect modulates appetite-related brain activity to images of food. Int $J$ Eat Disord 39, 357-363.

10. Killgore WD \& Yurgelun-Todd DA (2005) Developmental changes in the functional brain responses of adolescents to images of high and low-calorie foods. Dev Psychobiol 47, 377-397.

11. Davy SR, Benes BA \& Driskell JA (2006) Sex differences in dieting trends, eating habits, and nutrition beliefs of a group of Midwestern college students. J Am Diet Assoc 106, 1673-1677.

12. Wardle J, Haase AM, Steptoe A et al. (2004) Gender differences in food choice: the contribution of health beliefs and dieting. Ann Behav Med 27, 107-116.

13. Killgore WD \& Yurgelun-Todd DA (2010) Sex differences in cerebral responses to images of high versus lowcalorie food. Neuroreport 21, 354-358.

14. Cornier MA, Salzberg AK, Endly DC et al. (2010) Sex-based differences in the behavioral and neuronal responses to food. Physiol Behav 99, 538-543.

15. Rolls BJ, Hetherington M \& Burley VJ (1988) Sensory stimulation and energy density in the development of satiety. Physiol Behav 44, 727-733. 
16. Zhou B, Yamanaka-Okumura H, Adachi C et al. (2013) Agerelated variations of appetite sensations of fullness and satisfaction with different dietary energy densities in a large, free-living sample of Japanese adults. J Am Diet Assoc 113, $1155-1164$.

17. Furnham A \& Kirkcaldy B (1997) Age and sex differences in health beliefs and behaviours. Psychol Rep 80, 63-66.

18. Courtenay WH, McCreary DR \& Merighi JR (2002) Gender and ethnic differences in health beliefs and behaviors. J Health Psychol 7, 219-231.

19. Rolls BJ, Rolls ET, Rowe EA et al. (1981) Sensory specific satiety in man. Physiol Behav 27, 137-142.

20. Ministry of Health, Labour and Welfare of Japan (2009) Dietary Reference Intake for Japanese (2010). Tokyo: Daiichi Shuppan, Publishing Co., Ltd.

21. Hetherington MM \& Rolls BJ (1987) Methods of investigating human eating behavior. In Feeding and Drinking, pp. 77-109 [F Toates and $\mathrm{N}$ Rowland, editors]. Amsterdam: Elsevier Science Publishers.

22. Benelam B (2009) Satiation, satiety and their effects on eating behaviour. Nutr Bull 34, 126-173.

23. Stubbs RJ, Ritz P, Coward WA et al. (1995) Covert manipulation of the ratio of dietary fat to carbohydrate and energy density: effect on food intake and energy balance in freeliving men eating ad libitum. Am J Clin Nutr 62, 330-337.

24. Rolls BJ \& Bell EA (1999) Intake of fat and carbohydrate: role of energy density. Eur J Clin Nutr 53, Suppl. 1, S166-S173.

25. Mattes RD (1997) The taste for salt in humans. Am J Clin Nutr 65, 2 Suppl., 692S-697S.

26. Dransfield E (2008) The taste of fat. Meat Sci 80, 37-42.

27. Mattes RD (1985) Gustation as a determinant of ingestion: methodological issues. Am J Clin Nutr 41, 672-683.

28. Gemousakakis T, Kotini A, Anninos P et al. (2011) MEG evaluation of taste by gender difference. $J$ Integr Neurosci 10, $537-545$.

29. Kanarek RB, Ryu M \& Przypek J (1995) Preferences for foods with varying levels of salt and fat differ as a function of dietary restraint and exercise but not menstrual cycle. Physiol Behav 57, 821-826.
30. Leshem M, Abutbul A \& Eilon R (1999) Exercise increases the preference for salt in humans. Appetite 32, 251-260.

31. Bertino M, Beauchamp GK \& Engelman K (1982) Long-term reduction in dietary sodium alters the taste of salt. Am J Clin Nutr 36, 1134-1144.

32. Huggins RL, Di Nicolantonio R \& Morgan TO (1992) Preferred salt levels and salt taste acuity in human subjects after ingestion of untasted salt. Appetite 18, 111-119.

33. Drewnowski A (1989) Sensory preferences for fat and sugar in adolescence and adult life. Ann N Y Acad Sci 561, 243-250.

34. Mennella JA (2014) Ontogeny of taste preferences: basic biology and implications for health. Am J Clin Nutr 99, issue 3, 704S-711S

35. Drewnowski A (1995) Energy intake and sensory properties of food. Am J Clin Nutr 62, 5 Suppl., 1081S-1085S.

36. Rolls BJ (1995) Carbohydrates, fats, and satiety. Am J Clin Nutr 61, 4 Suppl., 960S-967S.

37. Rolls BJ \& Shide DJ (1994) Dietary fat and the control of food intake. In Appetite and Body Weight Regulation Sugar, Fat, and Macronutrient Substitutes, pp. 167-177 [JD Fernstrom and GD Miller, editors]. Boca Raton, FL: CRC Press Inc.

38. Riedy CA, Chavez M, Figlewicz DP et al. (1995) Central insulin enhances sensitivity to cholecystokinin. Physiol Behav 58, 755-760.

39. Williams DL, Baskin DG \& Schwartz MW (2006) Leptin regulation of the anorexic response to glucagon-like peptide-1 receptor stimulation. Diabetes 55, 3387-3393.

40. Figlewicz DP \& Benoit SC (2009) Insulin, leptin, and food reward: update 2008. Am J Physiol Regul Integr Comp Physiol 296, R9-R19.

41. Drewnowski A (1997) Why do we like fat? J Am Diet Assoc 97, 7 Suppl., S58-S62.

42. Ryan KK, Woods SC \& Seeley RJ (2012) Central nervous system mechanisms linking the consumption of palatable high-fat diets to the defense of greater adiposity. Cell Metab 15, 137-149.

43. Sun Q, Spiegelman D, van Dam RM et al. (2010) White rice, brown rice, and risk of type 2 diabetes in US men and women. Arch Intern Med 170, 961-969. 